\section{Now in paperback}

\section{Colloidal Dispersions}

R. B. RUSSEL, D. A. SAVILLE and

W. R. SCHOWALTER

This book covers the physical side of colloid science from the individual forces acting between micrometer-sized particles suspended in a liquid, through the resulting equilibrium and dynamical properties.

f24.95 net PB $0521426006 \quad 544$ pp. 1992 Cambridge Monographs on Mechanics and Applied Mathematics

\section{Comparison of Statistical Experiments}

\section{ERIK TORGERSEN}

This book is devoted to the various methods of comparing statistical experiments, it is essentially self-contained, requiring only some background in measure theory and functional analysis. A comprehensive treatment of the subject which will be an essential reference for mathematical staristicians.

f65.00 net HB $0521250307 \quad 704 \mathrm{pp} . \quad 1991$ Encyclopedia of Mathematics and its Applications 36

\section{Integral Equations and Applications \\ C. CORDUNEANU}

This book can be used for graduate courses on integral equations, as a reference for researchers, or to describe methods of application of the theory. f50.00 net HB $0521340502 \quad 416$ pp. 1991

\section{Perturbation Methods}

\section{E. J. $\mathrm{HINCH}$}

In this book the author presents the theory and techniques underlying such methods in a manner which will give the text wide appeal to students from a broad range of disciplines.

f30.00 net HB $0521373107 \quad 172$ pp. 1992

f12.95 net PB 0521378974

Cambridge Texts in Applied Mathematics

For further information contact Science Publicity at the Cambridge address.

To order any Cambridge book call our 24 hour ordering service on 0223325970 .

\section{Chaotic Behaviour of Deterministic Dissipative Systems}

M. MAREK and I. SCHREIBER

This is a graduate text surveying both the theoretical and experimental aspects of deterministic chaos. f45.00 net HB $0521321670 \quad 380$ pp. 1991

\section{Now in paperback}

\section{Perspectives of Nonlinear Dynamics}

Volumes 1 and 2

\section{E. ATLEE JACKSON}

'Anyone who has tried either to learn or teach nonlinear dynamics from the research texts will be relieved to have an accessible alternative.'

Ian Stewart, The Times Higher Education Supplement Volume 1:

E19.95 net PB $0521426324 \quad 528$ pp. 1992

Volume 2:

E19.95 net PB 0521426332630 pp. 1992

\section{Macroscopic Theories of Superfluids}

Edited by G. GRIOLI

Based on lectures from a meeting organised by the Accademia Nazionale dei Lincei with contributions from some of the leading researchers in the field. This book will be an invaluable survey for research workers in superfluidity.

f 30.00 net HB $052137572 \times 224$ pp. 1991

\section{Paperback reissue}

\section{The Mathematical Theory of Non-Uniform Gases}

An Account of the Kinetic Theory of Viscosity, Thermal Conduction and Diffusion in Gases

Third Edition

\section{SYDNEY CHAPMAN and T. G. COWLING}

This reissue presents a detailed account of the mathematical theory of viscosity, thermal conduction and diffusion, based on the solution of the Maxwell-Boltzman equations.

f22.95 net PB $052140844 \times \quad 448$ pp. 1991

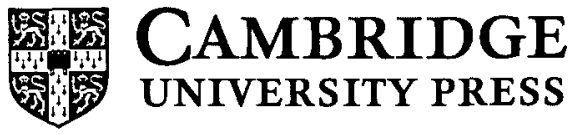

The Edinburgh Building, Cambridge CB2 2RU 
Submission of manuscripts Papers may be submitted to any member of the editorial board. Three copies should be sent: originals of figures should not be included until the paper has been accepted. Papers may be submitted electronically by sending a LaTeX file to EJAM@UK.AC.OX.VAX; this file should include the figures (line figures only). Electronic communications can also be used for minot corrections and for messages to the editors.

Layout of mamuscripts Papers should be typewritten in double spacing throughout, on one side of the paper. Please avoid footnotes if possible. Papers must begin with an abstract of not more than 300 words, and they should end with a brief concluding section. The SI system of units must be used throughout. There is no formal restriction on length, but the constraint of fitting an integral number of papers into 96 pages means that short papers (20 typed pages or fewer) are likely to appear sooner than long ones.

Illustrations Figures should be drawn in indian ink on good quality white paper. Wherever possible they will be reproduced with the author's lettering. A list of captions for figures should be attached separately.

Where appropriate, articles may be illustrated by photographs: high-quality glossy black and white prints are necessary.

References References should be listed in alphabetical order at the end of the main text. Please include the article title in the reference, which should be in the order: author's surname, initials: year in parentheses; article title; journal name, abbreviated in accordance with the World List of Scientific Periodicals (4th Edn): volume number (underlined); inclusive page numbers.

Citations in the text Any unambiguous system is acceptable. Three recommended ways of citing a 1992 paper by A. European are: European (1992); European [Eu]; European [7]. In the second case, the reference at the end of the text should be preceded by [Eu], and in the third by [7]. Please note that in the third system, alterationis may lead to wholesale renumbering.

\section{EDITORIAL POLICY}

The European Journal of Applied Mathematics aims to publish papers in all areas of applied mathematics, with especial emphasis on the following.

(i) The exposition of new mathematical ideas relevant to the modelling and analysis of modern technological processes.

(ii) The development of interesting mathematical methods with broad areas of applicability.

There is no restriction in the areas of applicability or the style of mathematics, although standard mathematical techniques will only be published if they are associated with novel applications or lead to substantial advances in established problem areas.

\section{COPYING}

This journal is registered with the Copyright Clearance Center, 27 Congress Street, Salem, MA 01970. Organisations in the USA who are also registered with the C.C.C. may therefore copy material (beyond the limits permitted by sections 107 and 108 of US copyright law) subject to payment to C.C.C. of the per-copy fee of \$5.00. This consent does not extend to multiple copying for promotional or commercial purposes. Code 0956$7925 / 92 \$ 5.00+.00$.

ISI Tear Sheet Service, 3501 Market Street, Philadelphia. Pennsylvania 19104, USA, is authorised to supply single copies of separate articles for private use only.

For all other use, permission should be sought from Cambridge or the American branch of Cambridge University Press. 


\section{European Journal of \\ Applied Mathematics}

VOLUME 3.PART 2.JUNE 1992

\section{CONTENTS}

Homoclinic orbits in the dynamic phase-space analogy of an elastic strut

C. J. AMICK and J. F. TOLAND

Diffraction of sound by a surface inhomogeneity at a fluid-solid interface

R. H. TEW

The Cahn-Hilliard gradient theory for phase separation with non-smooth free energy. Part II: Numerical analysis

J. F. BLOWEY and C. M. ELLIOTT

On the correctness of a phenomenological model of equilibrium phase transitions in a deformable elastic medium

A. M. MEIRMANOV and N. V. SHEMETOV

(C) Cambridge University Press 1992

CAMBRIDGE UNIVERSITY PRESS

The Pitt Building, Trumpington Street, Cambridge CB2 IRP

40 West 20th Street, New York, NY 10011-4211, USA

10 Stamford Road, Oakleigh, Victoria 3166, Australia

Printed in Great Britain by the University Press, Cambridge 